\title{
Effect of climate change on the thermal stratification of the baltic sea: a sensitivity experiment
}

\author{
R. Hordoir • H. E. M. Meier
}

Received: 24 November 2010/ Accepted: 21 February 2011/Published online: 4 March 2011

(C) The Author(s) 2011. This article is published with open access at Springerlink.com

\begin{abstract}
The evolution in time of the thermal vertical stratification of the Baltic Sea in future climate is studied using a 3D ocean model. Comparing periods at the end of the twentieth and twenty first centuries we found a strong increase in stratification at the bottom of the mixed layer in the northern Baltic Sea. In order to understand the causes of this increase, a sensitivity analysis is performed. We found that the increased vertical stratification is explained by a major change in re-stratification during spring solely caused by the increase of the mean temperature. As in present climate winter temperatures in the Baltic are often below the temperature of maximum density, warming causes thermal convection. Re-stratification during the beginning of spring is then triggered by the spreading of freshwater. This process is believed to be important for the onset of the spring bloom. In future climate, temperatures are expected to be usually higher than the temperature of maximum density and thermally induced stratification will start without prior thermal convection. Thus, freshwater controlled re-stratification during spring is not an important process anymore. We employed a simple box model and used sensitivity experiments with the $3 \mathrm{D}$ ocean model to delineate the processes involved and to quantify the impact of changing freshwater supply on the thermal stratification in the Baltic Sea. It is suggested that these stratification changes may have an important impact on vertical nutrient fluxes and the intensity of the spring bloom in future climate of the Baltic Sea.
\end{abstract}

R. Hordoir $(\bowtie) \cdot$ H. E. M. Meier

Swedish Meteorological and Hydrological Institute,

60176 Norrköping, Sweden

e-mail: robinson.hordoir@smhi.se
Keywords Baltic sea Climate change . Numerical modelling · Scenario simulation · Temperature of maximum density

\section{Introduction}

The Baltic Sea is one of the largest brackish waters in the world [377,400 km² (Sjöberg 1992)] and, although its dynamical features are very close to that of an oceanic basin in many aspects, its low salinity makes it a climatological niche (Stipa 2002; Stipa and Seppälä 2002). This specific feature is not only related to the ecosystem that may develop under such conditions, but also to the vertical stratification and connected vertical nutrient fluxes. The seasonal cycle of vertical stratification in the Baltic Sea has been extensively studied in previous studies (e.g., Eilola 1997; Eilola and Stigebrandt 1998). For instance, Eilola and Stigebrandt (1998) showed that the mechanism that enables the start of the spring stratification is related with the arrival of juvenile freshwater in the Baltic proper, which is the central area of the Baltic Sea. Eilola (1997) showed that after a cold winter the sea surface temperature (SST) can be often below the temperature of maximum density. Therefore, an increase of SST at spring time can increase the surface density and is unlikely to increase stratification above the permanent pycnocline before the entire mixed layer reaches the temperature of maximum density in a similar process as found in lakes (Farmer and Carmack 1981). The development of a spring thermocline before the entire mixed layer reaches the temperature of maximum density is therefore ensured only because of a lower surface salinity mostly related with the arrival of new freshwater in the Baltic proper. It was suggested that the transport of this juvenile freshwater is caused by either 
eddy diffusion (Stipa and Seppälä 2002) or by wind scattering (Eilola and Stigebrandt 1998).

However, the salinity decrease close to the surface coincides with a salinity increase below $30 \mathrm{~m}$ (Eilola 1997). Moreover, Eilola (1997) showed that only a sudden freshwater pulse can provide the haline surface stratification. This finding suggests that it is not a real transport of juvenile freshwater into the centre of the Baltic proper that ensures re-stratification but rather a wave. Hordoir and Meier (2010) showed that the actual arrival of juvenile freshwater occurs later at the end of the summer in the Baltic proper. The same tilting of salinity profiles as in observations was found in a non eddy-resolving model of the Baltic Sea confirming that only a wave could create such a sudden decrease of salinity.

In this study the above mentioned processes determining vertical stratification in the upper water column of the Baltic in future climate are investigated. We aim to answer the following questions: How will the seasonal cycle of stratification change in future climate? What will be the mechanisms that control it? These questions are addressed using a 3D ocean model driven by projected atmospheric forcing and data at the lateral boundary. Our strategy is to perform a series of sensitivity experiments in order to understand what drives the stratification increase. A simple box model is employed to explain the process.

In Sect. 2, the ocean model is presented and the forcing data set is introduced. In Sect. 3, we present results of these simulations both for the entire Baltic Sea and for selected cross-sections. We also formulate a hypothesis which explains these results. A box model is applied to underpin our hypothesis. Finally, the study is finalised in Sect. 4 with summary and conclusions.

\section{Methods and models}

\subsection{Circulation model}

We use the Rossby Centre Ocean model (RCO) which domain covers the entire Baltic Sea (Meier et al. 2003). It has a horizontal resolution of two nautical miles (about $3.7 \mathrm{~km}$ ). The 83 vertical layers are equally thick with a layer thickness of $3 \mathrm{~m}$. A mode splitting approach between barotropic and baroclinic modes is applied to reduce the computational burden. The baroclinic and barotropic time steps amount to 150 and $15 \mathrm{~s}$, respectively. The open boundary conditions in the northern Kattegat between Denmark and Sweden are based on prescribed sea surface heights (SSHs) at the lateral boundary and radiation conditions for baroclinic variables. In case of inflow temperature and salinity variables are nudged towards prescribed profiles. For a detailed model description the reader is referred to Meier et al. (2003) and Meier (2007).

Hordoir and Meier (2010) used atmospheric forcing data based upon a regionalised ERA40 re-analysis and observations both for runoff and at the open boundary in the northern Kattegat. In difference, in the present study atmospheric forcing data from a transient climate scenario simulation for 1960-2100 are used. These data were extracted from a simulation using the regional, coupled Rossby Centre Atmosphere Ocean model (RCAO) driven with lateral boundary data from the global climate model HadCM3 from the Hadley Centre in the UK (Gordon et al. 2000). In this simulation the greenhouse gas emission scenario A1B is assumed (Nakićenović et al. 2000).

For 1960-2007 monthly runoff data from observations are used. After 2007 runoff data are extracted randomly from the control period 1960-2007 and a trend is added. For 2008-2100 we considered three scenarios with no trend, $20 \%$ increase and $20 \%$ decrease of the runoff at the end of the century compared to the control period. Hence, in each of the three scenario simulations the inter-annual variability is identical because it is based upon the same randomly generated data.

At the open boundary in the northern Kattegat in case of inflow climatologically mean temperature and salinity profiles during the whole period 1960-2100 are nudged assuming that the water temperature changes in Kattegat are mainly related to air temperature changes and not to changes of horizontal advection following the approach by Meier (2006).

The main forcing function controlling the water exchange between the Baltic Sea and North Sea is the SSH at the lateral boundary in the northern Kattegat. Together with the wind fields over the region SSH drives salt water inflows and controls the salt content in the Baltic Sea (Gustafsson and Andersson 2001). In order to compute the SSH at the open boundary we use the approach by Gustafsson and Andersson (2001). Thus, SSH is computed from the meridional pressure gradient across the North Sea. This method is however extended in order to improve SSH variability of present climate. A statistical correction is applied in order to obtain the same SSH standard deviation during the control period than in observations. Test experiments indicate that salinity in the Baltic Sea decreases dramatically if no correction is applied. The reason for this artificial response is a too smooth horizontal SLP (Sea Level Pressure) gradient across the North Sea in both GCM and re-analysis driven simulations.

\subsection{Analysis details}

The analysis focused on two time slices of the transient simulation 1960-2100. The two periods, P1 and P2, cover 
1968-1999 and 2062-2093, respectively. Stratification changes between P2 and P1 were analysed. Seasonal mean vertical cross sections in some sub-basins (see Fig. 1 for cross section locations) of temperature, salinity and the Brunt-Väisälä frequency were investigated.

As mentioned above, the results of three sensitivity experiments were compared assuming runoff with no change, $20 \%$ increase and $20 \%$ decrease at the end of the century. In addition, cause-and-effect experiments were performed in order to understand the origin of changes in future climate. These cause-and-effect experiments basically studied the influence of wind changes between period P1 and P2, or the effect of any change of the forcing like relative humidity, cloudiness, etc. The experiments, which are not detailed in the present study, permitted to conclude that the changes in stratification structure were only related to air temperature changes. In order to concentrate on the effect of changing air temperature, we created an artificial forcing set that is applied after the control period P1. This forcing is created using a random distribution of years of atmospheric fields selected from the period P1. For each year later than 2007 (the last year of period P1) randomly a year of the period P1 was chosen for the wind forcing, cloudiness, solar radiation etc., but excluding air temperature. These artificial forcing fields are chosen to perform the experiments described in this article.

\subsection{Conceptual model}

A simplified conceptual model based on the relation between stratification and the expansion coefficient of a theoretical mixed layer in a brackish ocean is developed. This conceptual approach is not meant to give any realistic quantitative results but rather an explanation of the response of the seasonal thermocline in an estuary in warmer climate.
The model assumes that the thermal expansion coefficient $\alpha$ in an ocean where pressure has little influence depends linearly on temperature for a given salinity around the point of maximum density. Note that the thermal expansion coefficient is zero at the point of maximum density. Thus, we assume that the relation between $\alpha$ and $T-T_{m}$ can be considered as being linear close to the point of maximum density where $T$ and $T_{m}$ are temperature and the temperature of maximum density, respectively. Fitting this hypothesis to the $\alpha$ coefficient that can be computed based on the equation of state of sea water (e.g., Gill 1982), the expansion coefficient $\alpha$ expressed in $K^{-1}$ is assumed to be given by

$\alpha=\gamma\left(T-T_{m}\right)$

with $\gamma=1.53846 \times 10^{-5} K^{-2}$.

The model consists now of the following set of equations describing the seasonal thermocline for given salinity:

$\frac{d b}{d t}=\frac{\alpha g}{C_{p}} \nabla J_{q}$

$\rho C_{p} \frac{d T}{d t}=\nabla J_{q}$

$\nabla J_{q}=\frac{I_{\text {rad }}-I_{\text {long }}-F_{q}}{\delta z}$

$F_{q}=\rho C_{p} v_{t} \frac{\Delta T_{l}}{\delta z}$

$v_{t}=\left(\delta z\left(1-\beta \frac{b}{\rho \delta z s^{2}}\right)\right)^{2} s$

The variables are explained in Table 1. For basic equations the reader is referred to oceanographic text books (e.g. Gill 1982). Equation 2 assumes that buoyancy is independent of depth within the mixed layer and that it is only a function of the heat flux divergence into the mixed layer (Stipa and Seppälä 2002). Equation 3 assumes that the temperature is also constant within the mixed layer.
Fig. 1 Annual mean sea surface temperature $\left({ }^{\circ} \mathrm{C}\right)$ for $\mathrm{P} 1$ (left) and $\mathrm{P} 2$ (right). In addition, the locations of the three crosssections $A, B$ and $C$ are shown in the left panel
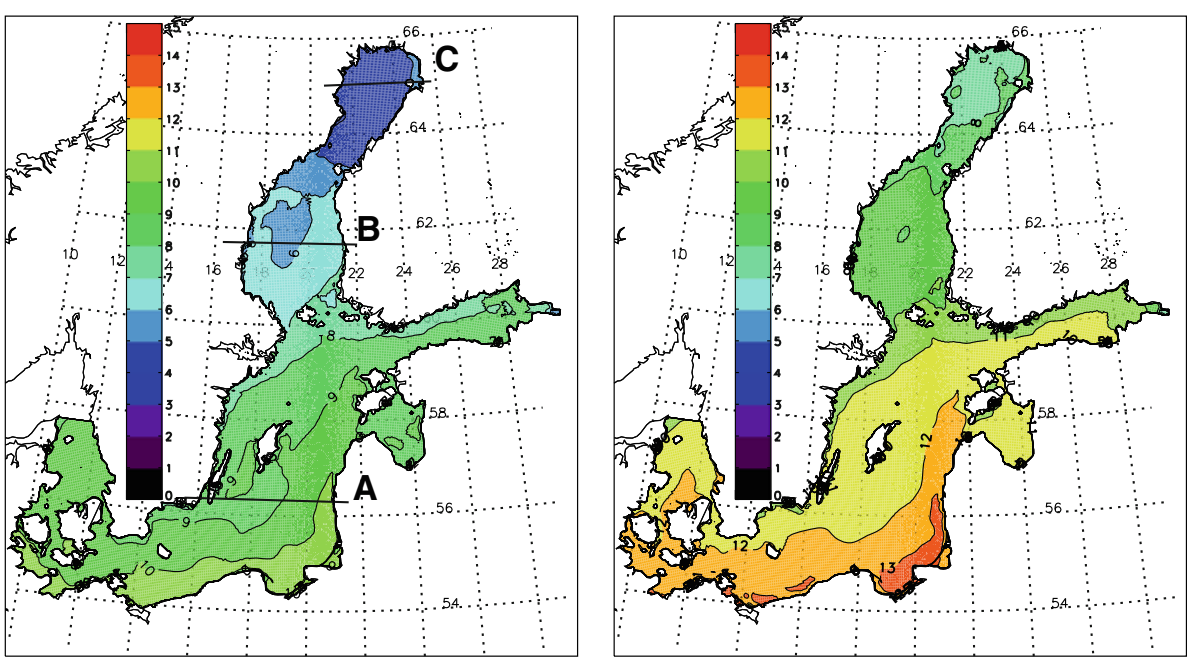
Table 1 Variables and parameters of the conceptual box model describing spring re-stratification in time $t$

\begin{tabular}{|c|c|c|}
\hline Name & Description & Comment \\
\hline$b$ & Buoyancy of the mixed layer $\left(\mathrm{N} \mathrm{m}^{-3}\right)$ & $\begin{array}{l}\text { Assumed to be uniform in the mixed layer. Closely related with } \\
\text { stratification its time evolution is computed for a period of } \\
100 \text { days }\end{array}$ \\
\hline$T$ & Temperature of the mixed layer $(\mathrm{K})$ & $\begin{array}{l}\text { Assumed to be uniform in the mixed layer. Its time evolution is } \\
\text { also computed for a period of } 100 \text { days }\end{array}$ \\
\hline$\alpha$ & Thermal expansion coefficient $\left(\mathrm{K}^{-1}\right)$ & Can be computed if temperature is known \\
\hline$J_{q}$ & Heat flux affecting the mixed layer $\left(\mathrm{W} \mathrm{m}^{-2}\right)$ & $\nabla J_{q}$ is calculated from Eq. 4. \\
\hline$I_{\text {rad }}$ & Solar radiation into the mixed layer $\left(\mathrm{W} \mathrm{m}^{-2}\right)$ & Is assumed to be constant and equal to $175\left(\mathrm{~W} \mathrm{~m}^{-2}\right)$ \\
\hline$I_{\text {long }}$ & Long wave net heat flux $\left(\mathrm{W} \mathrm{m}^{-2}\right)$ & Is assumed to be constant and equal to $50\left(\mathrm{~W} \mathrm{~m}^{-2}\right)$ \\
\hline$F_{q}$ & Heat flux leaving the mixed layer at its base $\left(\mathrm{W} \mathrm{m}^{-2}\right)$ & Is computed from Eq. 6 . \\
\hline$\rho$ & Density of sea water $\left(\mathrm{kg} \mathrm{m}^{-3}\right)$ & Is assumed to be constant and equal to $1,000 \mathrm{~kg} \mathrm{~m}^{-3}$ \\
\hline$C_{p}$ & Heat capacity of sea water $\left(\mathrm{J} \mathrm{K}^{-1} \mathrm{~kg}^{-1}\right)$ at constant pressure & Is assumed to be constant and equal to $4,000 \mathrm{~J} \mathrm{~kg}^{-1} \mathrm{~K}^{-1}$ \\
\hline$\Delta T_{l}$ & $\begin{array}{l}\text { Temperature difference between the mixed layer } \\
\text { and the lower layer }(\mathrm{K})\end{array}$ & Is assumed to be constant and equal to $+2^{\circ}$ \\
\hline$\delta z$ & Estimated depth of the mixed layer (m) & Is assumed to be constant and equal to $20 \mathrm{~m}$ \\
\hline$v_{t}$ & Diffusivity at the base of the mixed layer $\left(\mathrm{m}^{2} \mathrm{~s}^{-1}\right)$ & Computed based on a simple mixed layer model \\
\hline$\beta$ & Empirical coefficient & $\begin{array}{l}\text { Is assumed to be constant in order for } 1-\beta \frac{b}{\rho \delta z s^{2}} \text { to be positive } \\
\text { within the buoyancy domain. Its value is set to } 0.25\end{array}$ \\
\hline$s$ & Shear at the base of the mixed layer $\left(\mathrm{m} \mathrm{s}^{-1}\right)$ & $\begin{array}{l}\text { Is assumed to be constant based on a velocity gradient } \\
\text { of } 5 \mathrm{~cm} \mathrm{~s}^{-1}\end{array}$ \\
\hline
\end{tabular}

Equation 6 is a simplified mixing length turbulence model following Rodi (1993). In Eq. 6 the stratification frequency is approximated using the buoyancy $b$ and the length scale $\delta z$ in order to estimate the Richardson number $R_{i}=\frac{b}{\rho \delta z s^{2}}$. Based on this simplified approach the heat flux transmitted to the water column below the mixed layer depth and the heat fluxes into the mixed layer are estimated (Eqs. 5, 4).

The equations of the conceptual model are initialised with a buoyancy of $1 \mathrm{~N} \mathrm{~m}^{-3}$. The time evolution of the buoyancy is computed for a period of 100 days. Convergence is obtained for each time step based on a simple iteration method. Finally, for a given temperature the buoyancy at the end of the 100-day period is calculated and compared with the result for a given temperature which is $3^{\circ} \mathrm{C}$ higher. The calculation is performed for an initial temperature of $3^{\circ} \mathrm{C}$ below the temperature of maximum density and for another one with $2.5^{\circ} \mathrm{C}$ above the temperature of maximum density.

\section{Results}

\subsection{Scenario simulation with constant runoff}

\subsubsection{Increased thermal stratification during spring and summer}

Figure 1 shows the annual mean sea surface temperature (SST) during P1 and P2. One can notice an increase of SST of around $2-3^{\circ}$ in most parts of the Baltic Sea, which is consistent with the mean air temperature increase. This result could be expected if one looks at the annual mean temperature increase, and will therefore not be the main focus of this study that concentrates mostly on stratification changes.

Figures 2, 3 and 4 show the seasonal mean changes of the Brunt-Väisälä frequency and water temperature at the cross-sections A, B and C (for the locations see Fig. 1). A large increase of the stratification at the bottom of the mixed layer during spring and summer is observed. This increase is smaller for the southernmost sub-basins, but increases towards the North with highest values in the Bothnian Bay. For the northern sub-basins, this stratification increase at the bottom of the mixed layer during summer coincides with a stratification decrease below the mixed layer depth. We found that the stratification changes are mainly caused by water temperature changes. One can also notice that the stratification increase becomes more important as one goes from cross-section A towards crosssection $\mathrm{C}$. We shall see and explain later in the present article that this amplification of stratification increase from south towards north, correlates with mean water temperature decrease and/or salinity decrease from southern towards northern cross-sections.

Cause-and-effect studies were performed to investigate the impact of changing cloudiness, wind or air temperature. For instance, the increase of the stratification at the bottom of the mixed layer could have been caused by either 

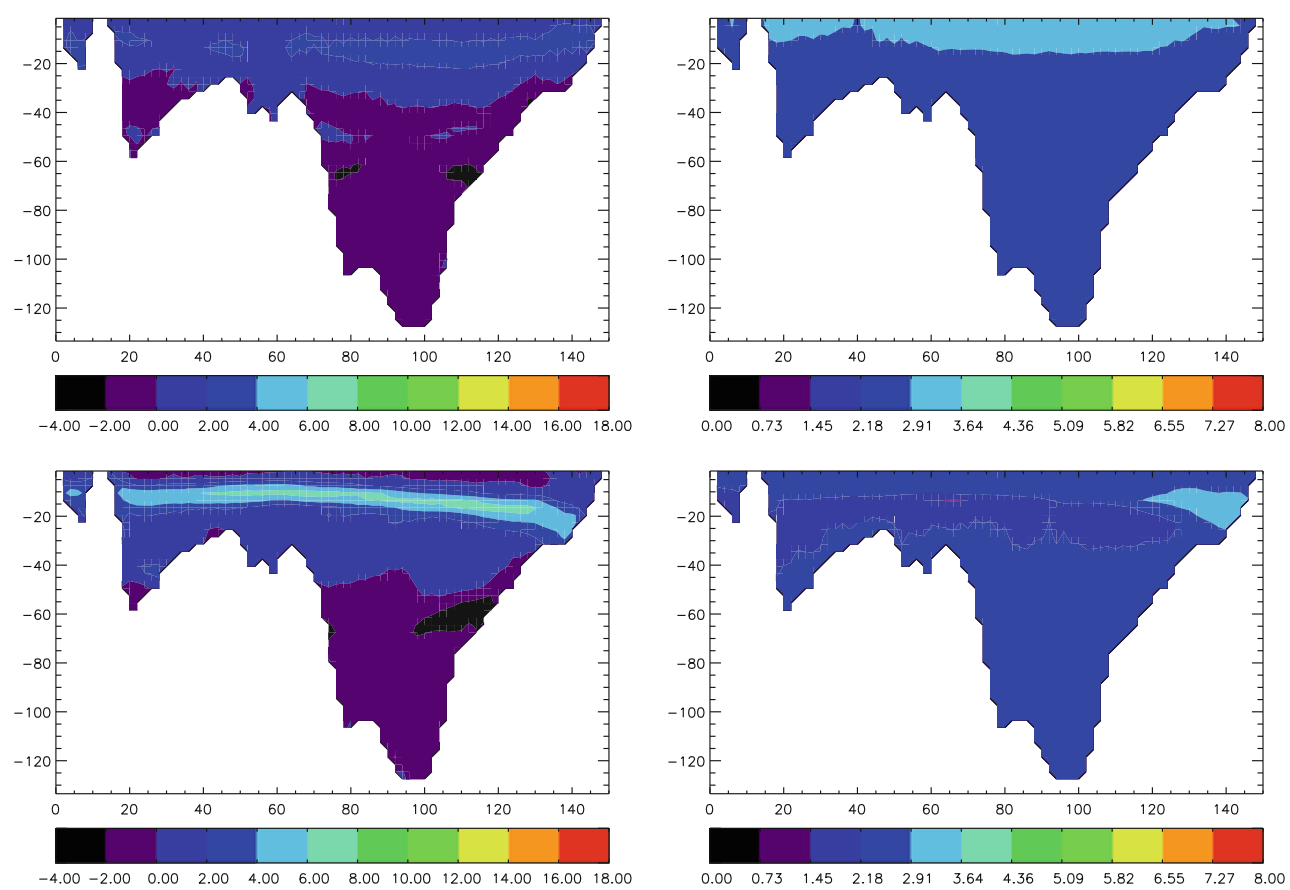

Fig. 2 Brunt-Väisälä frequency difference $(\mathrm{mHz})$ (left panels) and temperature difference $\left({ }^{\circ} \mathrm{C}\right.$ ) (right panels) for cross section $(A)$ during spring (March, April, May) (upper panels) and summer (June, July,

August) (lower panels). Values outside the range of the depicted colour bar are shown in white
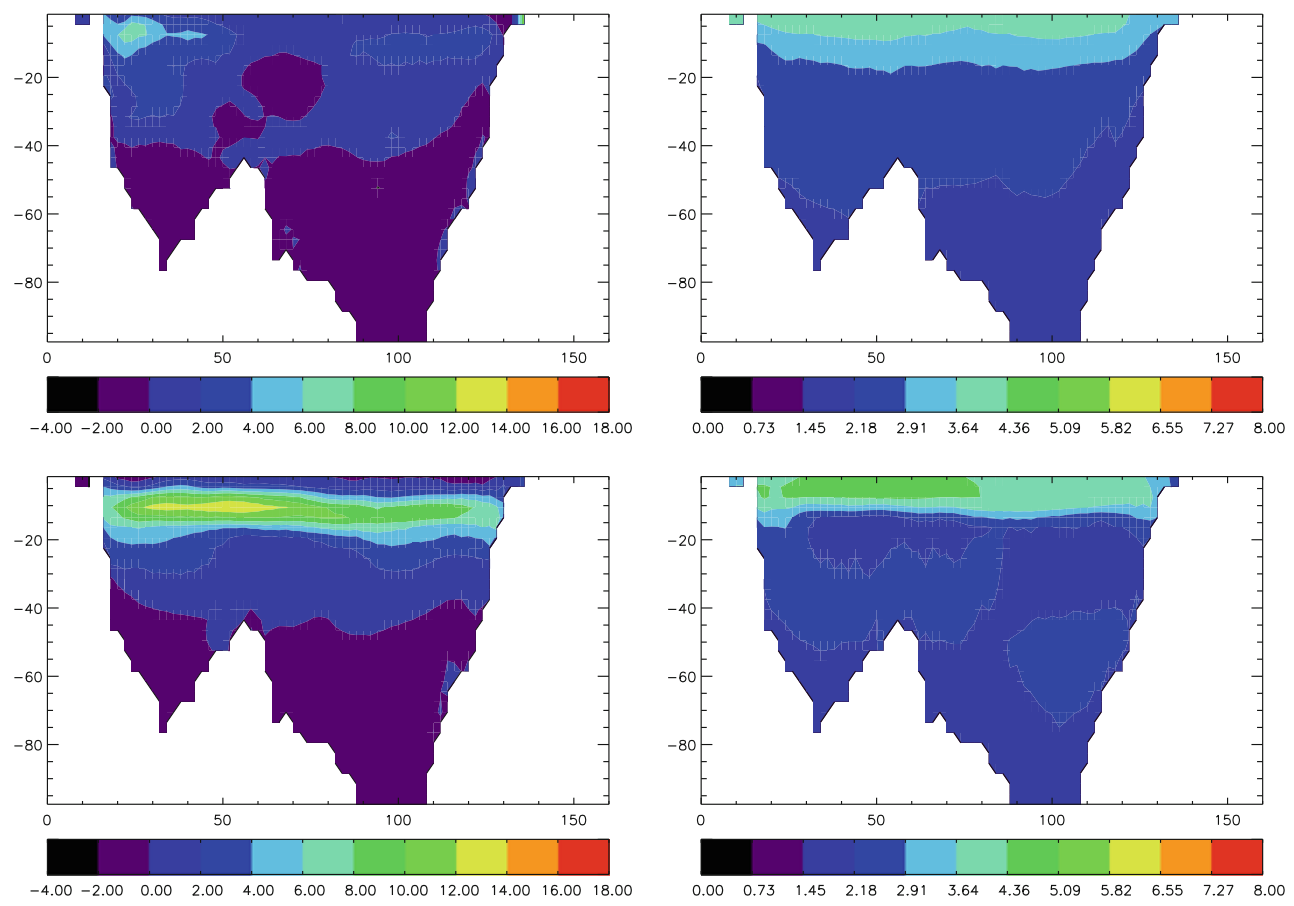

Fig. 3 Brunt-Väisälä frequency difference $(\mathrm{mHz})$ (left panels) and temperature difference $\left({ }^{\circ} \mathrm{C}\right)$ (right panels) for cross section $(B)$ during spring (March, April, May) (upper panels) and summer (June, July,

decreasing cloudiness or increasing wind speed in future climate during spring and summer. However, we found no significant impact from cloudiness changes or wind

August) (lower panels). Values outside the range of the depicted colour bar are shown in white

changes. Actually cloudiness increases slightly between P1 and $\mathrm{P} 2$, and we could not find any significant wind regime changes. 

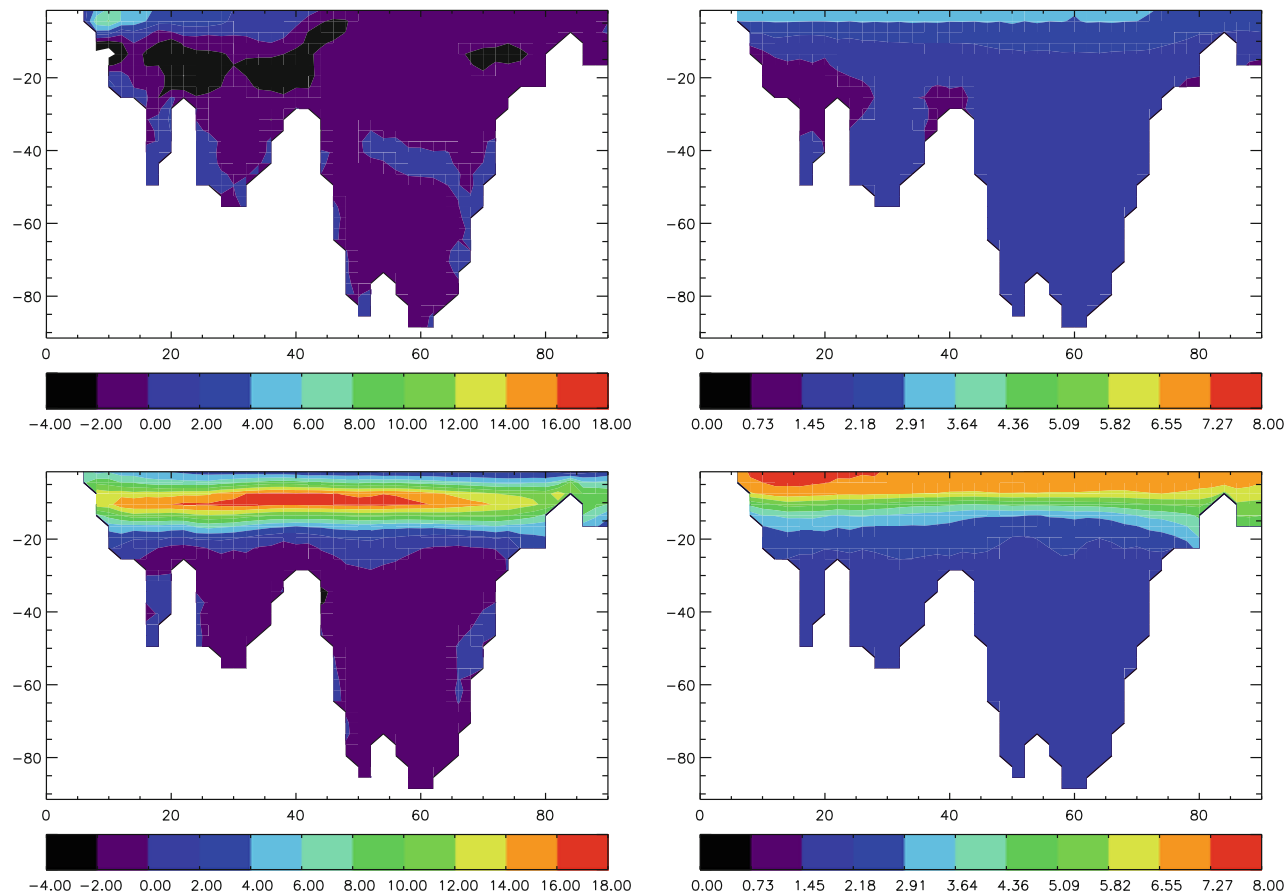

Fig. 4 Brunt-Väisälä frequency difference (mHz) (left panels) and temperature difference $\left({ }^{\circ} \mathrm{C}\right)$ (right panels) for cross section $(C)$ during spring (March, April, May) (upper panels) and summer (June, July,

Finally, we found that increasing air temperature and specific humidity explain the thermal stratification changes at the bottom of the mixed layer indicating a lack of thermal convection during spring in future climate. Figure 5 shows the mean temperature profiles for present and future climates at the three cross-sections. The profile for the temperature of maximum density is also shown.

Figure 5 shows an increase of temperature in all subbasins. Below the surface layer with a pronounced seasonal cycle the temperature increases with about $3^{\circ} \mathrm{C}$. Also the increase of the thermal stratification from South towards North is visible.

The stratification increase might be caused either by a changing thermal expansion coefficient or by a changing seasonal cycle of de-stratification and re-stratification or by both (cf. Eq. 3 by Stipa and Seppälä 2002). A change in the seasonal cycle of de-stratification and re-stratification can be caused by the lack of ice (Meier et al. 2004, 2011), which enables a faster spring re-stratification due to changes in the ice-albedo. However, the temperature profiles of Fig. 5 suggest that the lack of sea ice is not the only reason for a delayed thermal re-stratification during present climate (P1). The physics associated with the value of the expansion coefficient should also be considered, and they are for the case of brackish water, heavily related with the value of the temperature of maximum density.

Winter water temperatures may be lower than the temperature of maximum density and thermal convection

August) (lower panels). Values outside the range of the depicted colour bar are shown in white

during the spring heating period may delay re-stratification as well. Usually the water temperature in the Bothnian Bay is at the temperature of maximum density when the sea ice has vanished already. Thus, in all areas of the Baltic Sea with winter SSTs at least occasionally below the temperature of maximum density stratification can not start before thermal convection has occurred or before spreading juvenile freshwater has caused a haline re-stratification (Fig. 5; cf. Eilola 1997; Hordoir and Meier 2010).

In future climate (P2) water temperatures in the Baltic proper and Bothnian Sea are always higher than the corresponding temperatures of maximum density (Fig. 5). Thus, thermal convection during spring will not occur anymore. Only in the Bothnian Bay winter temperatures will be lower than the temperature of maximum density. Therefore, for most areas of the Baltic Sea re-stratification during spring will become independent of the spreading of juvenile freshwater which enables an earlier start of the re-stratification and consequently higher vertical stratification during summer (Figs. 2, 3 and 4). This influence of juvenile freshwater spreading was shown by Eilola (1997) to occur at the end of April or beginning of May, which coincides well with the results obtained by Hordoir and Meier (2010). Our results suggest that the spring stratification above the temperature of maximum density could happen before, thus decoupling the thermal stratification from the haline stratification. 

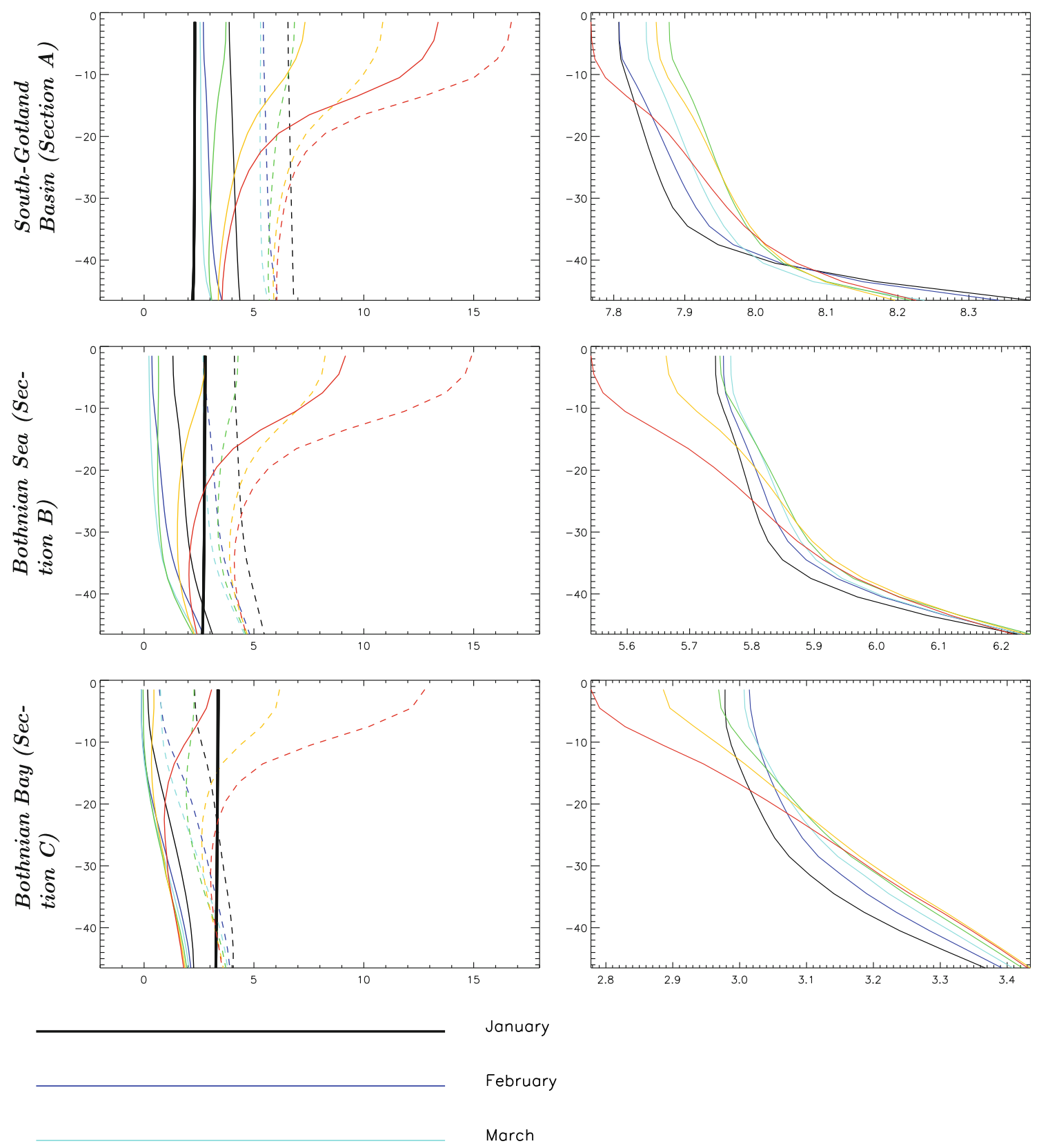

\section{April \\ Moy \\ June}

Fig. 5 Temperature and salinity profiles at the three cross-sections $A$ (South-Gotland Basin), B (Bothnian Sea) and $C$ (Bothnian Bay) for January to June (see colour code) for P1 (solid lines) and P2 (dashed lines). The black thick line shows the temperature of maximum

In the Bothnian Bay SSTs during May in future climate (P2) will be relatively high. In present climate (P1) May is still a month with cold SSTs below the temperature of maximum density and lower than bottom temperatures. density variation range. The seasonal cycle of salinity shows the spring stratification increase that contributes to start spring re-stratification in present climate (Eilola 1997)

Such a situation can only occur in cold brackish water bodies like the Baltic Sea. In the Bothnian Bay the spring mean temperature change between $\mathrm{P} 2$ and $\mathrm{P} 1$ results in a decrease of stratification because water masses located 

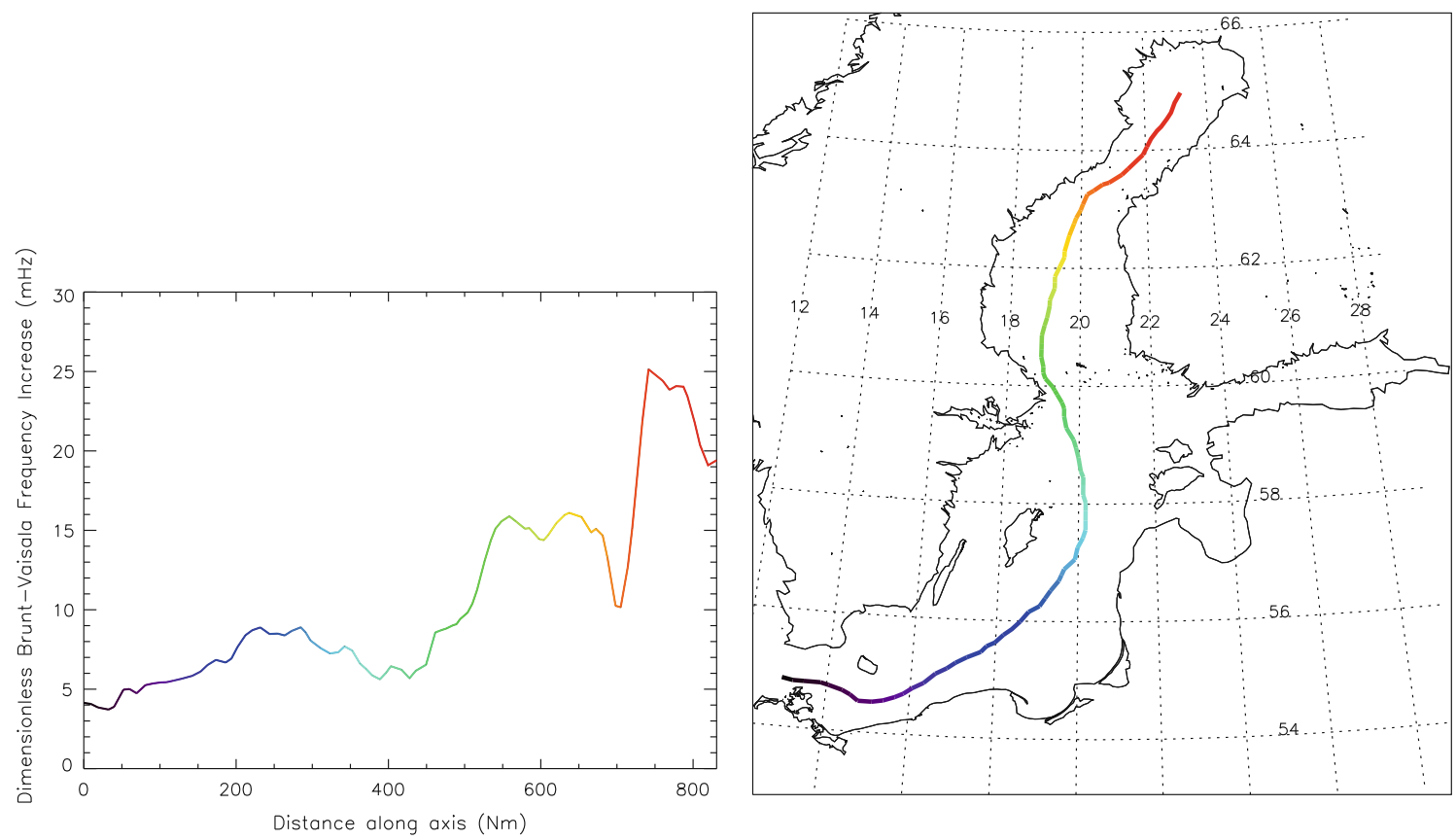

Fig. 6 Summer Brunt-Väisälä frequency differences at the base of the mixed layer (left panel) as a function of distance along a path through the Baltic (right panel). The colour scale allows to identify the location of the Brunt-Väisälä frequency changes along the path

below the mixed layer will be warmer, and therefore heavier (Fig. 4).

We conclude that in the Baltic Sea a change of spring and summer re-stratification due to climate change can be expected. In present climate the re-stratification during spring results from the combined effect of the baroclinic freshwater wave occurring at spring time (Hordoir and Meier 2010) and from increasing surface heat fluxes. As a consequence the surface layer will get stratified during spring with temperatures below the temperature of maximum density. In future climate the temperature increase results in higher values of the expansion coefficient and in a lack of thermal convection during spring in some areas of the Baltic. In most sub-basins the arrival of juvenile freshwater (or to be precise the surface salinity decrease, see Hordoir and Meier 2010) is not a pre-requisite for the spring re-stratification anymore when winter temperatures are below the temperature of maximum density (Eilola 1997). Higher water temperature in future climate will mean that winter temperatures are either always above the temperature of maximum density or rather close to this limit which would enable a faster thermal re-stratification. Re-stratification will become more controlled by the thermal expansion coefficient.

However, a main question remains unanswered. Why is the future stratification increase larger in the northern than in the southern Baltic? Of course, we have already mentioned in the present article that the lack of ice could explain partially this effect, but it cannot explain entirely this effect as ice has often already disappeared in many regions of the Bothnian Sea for example when spring/ summer restratification occurs. Therefore further investigation is required.

\subsubsection{Amplification of the effect from south towards north}

Figure 6 shows the increase of the Brunt-Väisälä frequency along a path through the Baltic Sea in summer. Correlating the stratification changes with either summer mean salinity or temperature anomalies with respect to the southern most location of the investigated path results in explained correlation coefficients $r^{2}$ of 0.85 and 0.9 for salinity and temperature, respectively. These significant correlations show that the stratification increase in future climate is larger in colder and/or fresher water.

To better understand the process of changing spring stratification we have employed a box model (Sect. 2.3). For each initial temperature $\left(T_{\text {init }}\right)$ we have computed the buoyancy evolution during 100 days (Fig. 7). Warming causes buoyancy differences of 7.16 , and $4.8 \mathrm{~N} \mathrm{~m}^{-3}$ when the temperature is $3^{\circ} \mathrm{C}$ below and $2.5^{\circ} \mathrm{C}$ above the temperature of maximum density, respectively.

In the first case of a temperature of $3^{\circ} \mathrm{C}$ below the temperature of maximum density $\mathrm{P} 1$ is characterised by decreasing and stagnating buoyancy while the water column is warming during spring whereas in P2 buoyancy increases immediately.

On the contrary, in the second case of a temperature of $2.5^{\circ} \mathrm{C}$ above the temperature of maximum density the 


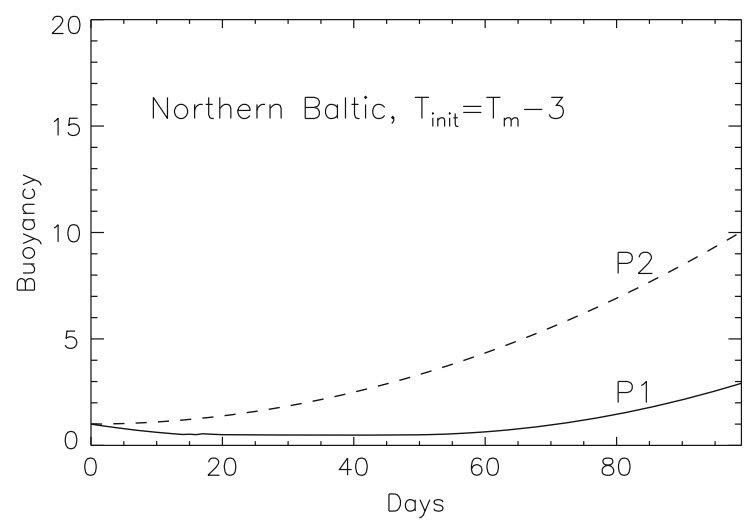

Fig. 7 Buoyancy evolutions during spring (in $\mathrm{N} \mathrm{m}^{-3}$ ) simulated with the conceptual box model in P1 (solid line) and P2 (dashed line). The left and right panels show the buoyancy evolution when the

evolution of the stratification in time in $\mathrm{P} 1$ and $\mathrm{P} 2$ are much closer than in the first case. Spring heating has a smaller impact on the buoyancy increase for temperatures above than for temperatures below the temperature of maximum density. For a temperature increase of temperatures already higher than the temperature of maximum density the impact of the shutdown of thermal convection is not important. On the other hand, for places where present climate temperature is close or even below the temperature of maximum density, a temperature increase will cause a larger buoyancy difference at the end of the heating period by solar radiation. This explains also the high degree of correlation found between stratification increase and both present climate temperature and salinity difference anomalies.

\subsection{Scenario simulations with increased or decreased runoff}

We made two additional simulations with different runoff datasets. In these experiments runoff is increased or decreased by $20 \%$ at the end of the century. In the following, only air temperature and specific humidity changes are considered as atmospheric forcing in future climate as described above.

Figure 8 shows the mean vertical profiles of stratification changes in June for the three simulations (constant, increasing and decreasing runoff). Decreasing runoff increases the thermal stratification at the bottom of the mixed layer compared to the reference experiment with constant runoff. At each cross section this change of stratification occurs precisely at the same depth at which the maximum of stratification increase is located (Figs. 2, 3 and 4). This depth is well below the depth range of seasonal salinity changes.

On the other hand, higher runoff limits the effect of thermal stratification increase. This behaviour is closely

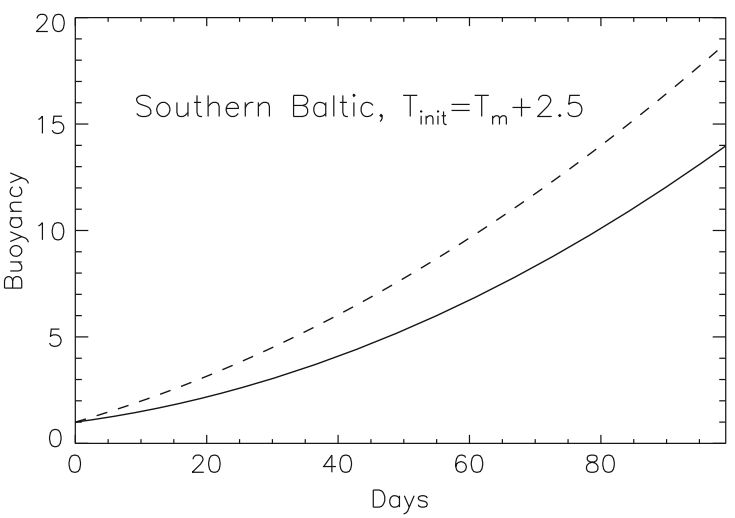

temperature is $3^{\circ} \mathrm{C}$ below and $2.5^{\circ} \mathrm{C}$ above the temperature of maximum density in $\mathrm{P} 1$, respectively

related with the brackish nature of the Baltic Sea. Low salinity in brackish environments results on having temperatures located close to the temperature of maximum density causing changes of the physical behaviour of the water masses whenever the temperature will change. Below the depth of maximum stratification increase, stratification differences between the three simulations are actually smaller. This confirms that the thermal stratification is closely related with the brackish nature of the Baltic Sea. By changing the runoff into the Baltic Sea, the mean salinity is altered (about \pm 2 PSU salinity changes) causing a change in the temperature of maximum density.

\section{Summary and conclusions}

In this study, we have focused our attention on future stratification changes in the upper part of the water column. Based on numerical model results, we have shown that there might be a switch between processes controlling the seasonal cycle of stratification in the Baltic Sea at the end of the twenty first century. Based on the first set of our sensitivity experiments we could show that only the air temperature increase was responsible for the increased stratification at the bottom of the mixed layer. In the scenario simulation neither a change in wind forcing nor a change in solar radiation was detected that would explain this change in stratification.

In future climate, changing spring and summer stratification at the bottom of the mixed layer will increase towards the North. We found that the impact of warmer temperatures on the stratification will be larger at places where in present climate mean temperatures are below the temperature of maximum density during most of the year. This is explained by the occurrence of thermal convection which delays thermal re-stratification in present climate. In future climate the mean temperatures will be larger than 

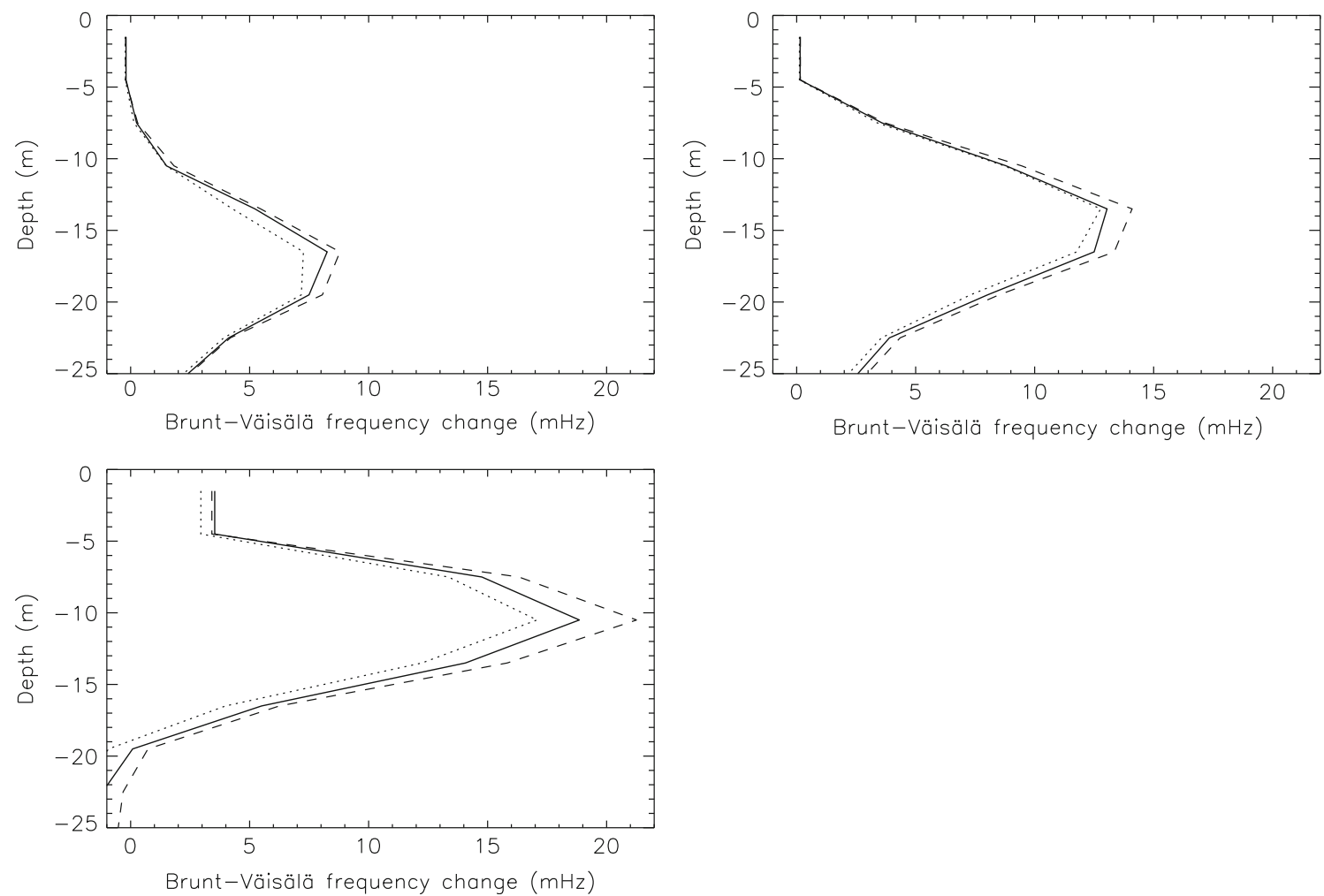

Fig. 8 Brunt-Väisälä frequency differences $(\mathrm{mHz})$ between $\mathrm{P} 2$ and $\mathrm{P} 1$ at the three cross-sections $A, B$ and $C$ for constant (solid line), increasing (dotted line) and decreasing runoff (dashed line)

the temperature of maximum density and the spring and summer stratification will be stronger.

Based on a second set of sensitivity experiments in which the runoff changes towards the end of the twenty first century, we confirmed that the change of stratification is due to the brackish nature of the Baltic Sea. Larger runoff would mean lower salinity and higher temperature of maximum density. Hence, if river runoff will increase in the Baltic Sea in future climate, spring and summer water temperatures will not necessarily be larger than the temperature of maximum density and spring re-stratification might be delayed due to thermal convection as in present climate. A decrease in runoff would of course create the opposite effect, that is an even greater increase of spring and summer thermal stratification.

The brackish nature of the Baltic Sea is mainly responsible for this behaviour. The relatively cold temperatures in the Baltic Sea are close to the temperature of maximum density, that is the point where the expansion coefficient can become zero. In the present case, the main change of the physical behaviour of the Baltic Sea comes from a switch from a cycle in which the expansion coefficient may be positive or negative into a cycle with only positive values. Because of this brackish nature in conjunction with cold temperatures, we conclude that climate change might affect stratification during the spring bloom significantly. The impact of a larger stratification at the bottom of the mixed layer on biogeochemical cycles will be investigated in future studies.

Acknowledgments The work presented in this study was jointly funded by the Swedish Environmental Protection Agency (SEPA, ref. no. 08/381) and the European Community's Seventh Framework Programme (FP/2007-2013) under grant agreement no. 217246 made with the joint Baltic Sea research and development programme BONUS (http://www.bonusportal.org) within the ECOSUPPORT project (http://www.baltex-research.eu/ecosupport). The RCO model simulations were partly performed on the climate computing resources 'Ekman' and 'Vagn' jointly operated by the Centre for High Performance Computing (PDC) at the Royal Institute of Technology (KTH) in Stockholm and the National Supercomputer Centre (NSC) at Linköping University. 'Ekman' and 'Vagn' are funded by a grant from the Knut and Alice Wallenberg foundation. We wish to thank the two anonymous reviewers for their work that helped to improve this manuscript.

Open Access This article is distributed under the terms of the Creative Commons Attribution Noncommercial License which permits any noncommercial use, distribution, and reproduction in any medium, provided the original author(s) and source are credited.

\section{References}

Eilola K (1997) Development of a spring thermocline at temperatures below the temperature of maximum density with application to the Baltic Sea. J Geophys Res 102(C4):8657-8662 
Eilola K, Stigebrandt A (1998) Spreading of juvenile freshwater in the Baltic proper. J Geophys Res 103(C12):27,795-27,807

Farmer D, Carmack E (1981) Wind mixing and restratification in a lake near the temperature of maximum density. J Phys Oceanogr 11:1516-1533

Gill A (1982) Atmosphere-ocean dynamics. Academic Press, London

Gordon C, Cooper C, Senior C, Banks H, Gregory J, Johns T, Mitchell J, Wood R (2000) The simulation of sst, sea ice extents and ocean heat transports in a version of the hadley centre coupled model without flux adjustments. Clim Dyn 16:47-168

Gustafsson BG, Andersson HC (2001) Modeling the exchange of the baltic sea from the meridional atmospheric pressure difference across the north sea. J Geophys Res 106:19,731-19,744

Hordoir R, Meier HEM (2010) Freshwater fluxes in the baltic seaa model study. J Geophys Res. doi:10.1029/2009JC005604

Meier H, Eilola K, Almroth E (2011) Climate-related changes in marine ecosystems simulated with a three-dimensional coupled biogeochemical-physical model of the baltic sea. Clim Res, (in press)

Meier HEM (2006) Baltic Sea climate in the late twenty-first century: a dynamical downscaling approach using two global models and two emission scenarios. Clim Dyn 27(1):39-68
Meier HEM (2007) Modeling the pathways and ages of inflowing salt- and freshwater in the Baltic Sea. Estuar Coast Shelf Sci 74:717-734

Meier HEM, Döscher R, Faxén T (2003) A multiprocessor coupled ice-ocean model for the Baltic Sea: application to salt inflow. J Geophys Res 108(C8):3273. doi:10.1029/2000JC000,521

Meier HEM, Döscher R, Halkka A (2004) Simulated distributions of Baltic sea-ice in warming climate and consequences for the winter habitat of the Baltic ringed seal. Ambio 33:249-256

Nakićenović N, Alcamo J, Davis G, de Vries B, and 24 others (2000) Emission scenarios. A special report of working group III of the intergovernmental panel on climate change, Cambridge University Press, Cambridge, 599 pp

Rodi W (1993) Turbulence models and their application in hydraulics: a state of the-art review, IAHR/AIRH

Sjöberg B (ed) (1992) Sea and coast. The National Atlas of Sweden, Almqvist and Wiksell International, Stockholm, Sweden, 128 pp

Stipa T (2002) Temperature as a passive isopycnal tracer in salty spiceless oceans. Geophys Res Lett 7:335-342

Stipa T, Seppälä J (2002) The fragile climatological niche of the baltic sea. Boreal Environ Res 7:335-342 